\title{
Sistem Pelacakan Objek Menggunakan Kombinasi Algoritma Optical Flow dan Template Matching
}

\author{
Ahmad Fahriannur ${ }^{1)}$, Ronny Mardiyanto ${ }^{2)}$, Meilana Siswanto ${ }^{1, *}$ \\ ${ }^{1)}$ Fakultas Teknik, Politeknik Negeri Jember \\ Jalan Mastrip Kotak Pos 164 Jember, Jawa Timur 68121 \\ 2) Jurusan Elektro, Institut Teknologi Sepuluh Nopember \\ Jalan Raya ITS, Keputih, Sukolilo, Keputih, Sukolilo, Surabaya, Jawa Timur 60111
}

Cara sitasi: A. Fahriannur, R. Mardiyanto, and M. Siswanto, "Sistem Pelacakan Objek Menggunakan Kombinasi Algoritma Optical Flow dan Template Matching," Jurnal Teknologi dan Sistem Komputer, vol. 6, no. 1, Jan. 2018. doi: 10.14710/jtsiskom.6.1.2018.13-17, [Online].

\begin{abstract}
This study is aimed to develop a tracking system algorithm by combining optical flow and template matching algorithms to strengthen tracking and minimize the resulting errors. The system has been tested on a football video game with the ball as a tracking object. The optical flow and template matching algorithms are used interchangeably based on the coordinates of both ranges calculated using the Euclidean distance equation. The result shows that the system is able to do tracking, although it is temporarily blocked by other objects, more stable and the distance error between the coordinates of the tracking result and the actual coordinates is not more than 110 pixels compared to using only optical flow or template matching algorithm.
\end{abstract}

Keywords - tracking; object; optical flow; template matching

\begin{abstract}
Abstrak - Penelitian ini bertujuan mengembangkan algoritma sistem pelacakan dengan cara menggabungan algoritma optical flow dan template matching untuk memperkuat pelacakan dan memperkecil galat yang dihasilkan. Sistem telah diujikan pada video permainan sepak bola dengan bola sebagai objek yang dilacak. Algoritma optical flow dan template matching digunakan secara bergantian berdasarkan koordinat jarak keduanya yang dihitung menggunakan persamaan jarak Euclidean. Hasil yang diperoleh menunjukkan sistem dapat melakukan pelacakan meskipun terhalang sesaat oleh objek lain dan lebih stabil serta galat jarak antara koordinat hasil pelacakan dan koordinat sebenarnya tidak lebih dari 110 piksel dibandingkan hanya menggunakan algoritma optical flow atau template matching saja.
\end{abstract}

Kata Kunci - pelacakan; objek; optical flow; template matching

\footnotetext{
*) Penulis korespondensi (Meilana Siswanto)
}

Email: msiswanto@gmail.com

\section{Pendahuluan}

Pengolahan Citra merupakan disiplin ilmu yang telah banyak diterapkan di perangkat-perangkat teknologi saat ini, misalnya untuk rekonstruksi citra 3 dimensi, pengenalan pola, pengawasan lingkungan, dan kamera keamanan [1]. Pengawasan lingkungan dan kamera keamanan menggunakan algoritma pelacakan merupakan bagian dari disiplin ilmu pengolahan citra. Sistem pelacakan merupakan sistem yang dapat mendeteksi salah satu atau beberapa objek tertentu ketika objek dalam keadaan diam atau bergerak [2].

Penelitian di bidang pelacakan dapat dilakukan menggunakan kamera atau video. Terdapat dua tahap dalam menganalisis video yaitu deteksi salah satu objek bergerak dan pelacakan objek dari frame ke frame [3]. Algoritma yang digunakan pada umumnya adalah optical flow, background substraction, template matching, camshift, meanshift, dan filter Kalman. Optical flow dapat melakukan pelacakan dengan stabil tetapi akan terjadi galat yang cukup besar jika objek terhalang sesaat [4], [5]. Algoritma template matching memiliki karakteristik yang berkebalikan dengan algoritma optical flow, yaitu dapat melakukan pelacakan meskipun objek terhalang sesaat tetapi kurang stabil [4], [6], [7]. Metode pelacakan lainnya adalah dengan menggunakan kamera PTZ, seperti yang dilakukan oleh Lalonde dkk. [8]. Metode ini dapat melakukan pelacakan posisi menggunakan algoritma background substraction dan dilakukan perbesaran objek dengan memanfaatkan fitur zoom.

Kombinasi algoritma pelacakan telah dilakukan dalam [9] dan [10] untuk mendapatkan keunggulan masing-masing algoritma. Prabhakar dkk. [9] mengembangkan sistem pelacakan video menggunakan algoritma frame differencing. Deteksi objek dilakukan dengan cara frame sekarang dikurangi dengan frame sebelumnya dan di antara objek yang terdeteksi dipilih salah satu objek menggunakan template matching. Hal ini mempercepat proses komputasinya dibandingkan dengan hanya menggunakan template matching saja. Parrila dkk. [10] membangun sistem pelacakan pada video lalu lintas jalan raya dengan menggunakan algoritma optical flow yang handal, yaitu dapat terus 


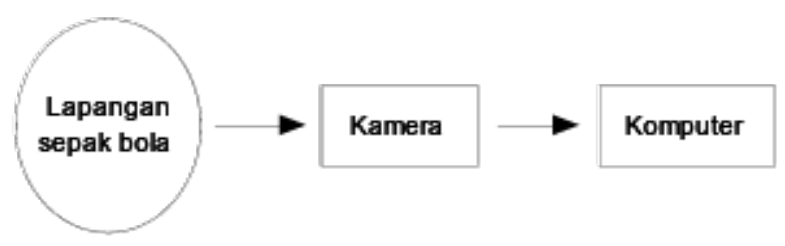

Gambar 1. Blok diagram sistem

melakukan pelacakan meskipun terhalang sesaat. Sistem tersebut dibangun menggunakan kombinasi algoritma adaptive filter, neural-network, dan optical flow. Penelitian ini bertujuan untuk mengembangkan sistem pelacakan objek pada video sepak bola dengan cara menggabungkan algoritma optical flow dan template matching untuk memperkuat pelacakan dan memperkecil galat yang dihasilkan.

\section{Metode Penelitian}

Sistem yang dibangun adalah sistem pelacakan objek dalam suatu permainan sepak bola. Pengguna akan memilih salah satu objek yaitu bola sepak. Kamera ditempatkan dalam lapangan sepak bola dan hasil capture kamera diolah ke dalam komputer seperti yang blok diagramnya ditunjukkan dalam Gambar 1. Sistem tersebut disimulasikan dengan cara mengunggah video permainan sepak bola dan dilakukan ekstraksi fitur untuk pelacakan objek bola sepak. Algoritma pelacakan yang digunakan adalah optical flow dengan jenis Lucas-Kanade menggunakan metoda citra Pyramid dan template matching seperti dalam [11], [12]. Pembuatan program menggunakan pustaka perangkat lunak OpenCV 2.1. Diagram alir program ditunjukkan dalam Gambar 2.

Ketika program dijalankan, pengguna memilih objek menggunakan mouse. Objek berupa bola sepak berukuran $10 \times 12$ piksel. Objek dilacak menggunakan optical flow dan template matching. Namun, hasil pelacakan yang ditampilkan adalah hasil optical flow. Jarak koordinat hasil pelacakan dihitung dari kedua algoritma tersebut seperti yang ditunjukkan dalam Gambar 3 menggunakan Persamaan 1, seperti dalam [13]-[15]. Jika jaraknya lebih dari 10 piksel, maka dilakukan update koordinat dengan cara koordinat pelacakan menggunakan optical flow digantikan dengan koordinat pelacakan template matching. Keadaan ini dilakukan setiap frame ke 20 dari total frame yang digunakan sebanyak 474 frame dan hasil koordinatnya disimpan dalam tipe file .txt.

Perhitungan nilai galat hasil pelacakan dilakukan dengan cara menghitung jarak koordinat seperti yang ditunjukkan dalam Persamaan 1.

$$
D=\sqrt{(a-x)^{2}+(b-y)^{2}}
$$

Dimana:

$\mathrm{a}=$ koordinat sebenarnya piksel sumbu-x

$\mathrm{b}=$ koordinat sebenarnya piksel sumbu-y

$\mathrm{x}=$ koordinat pelacakan piksel sumbu- $\mathrm{x}$

$\mathrm{y}=$ koordinat pelacakan piksel sumbu-y

$\mathrm{D}=$ galat jarak

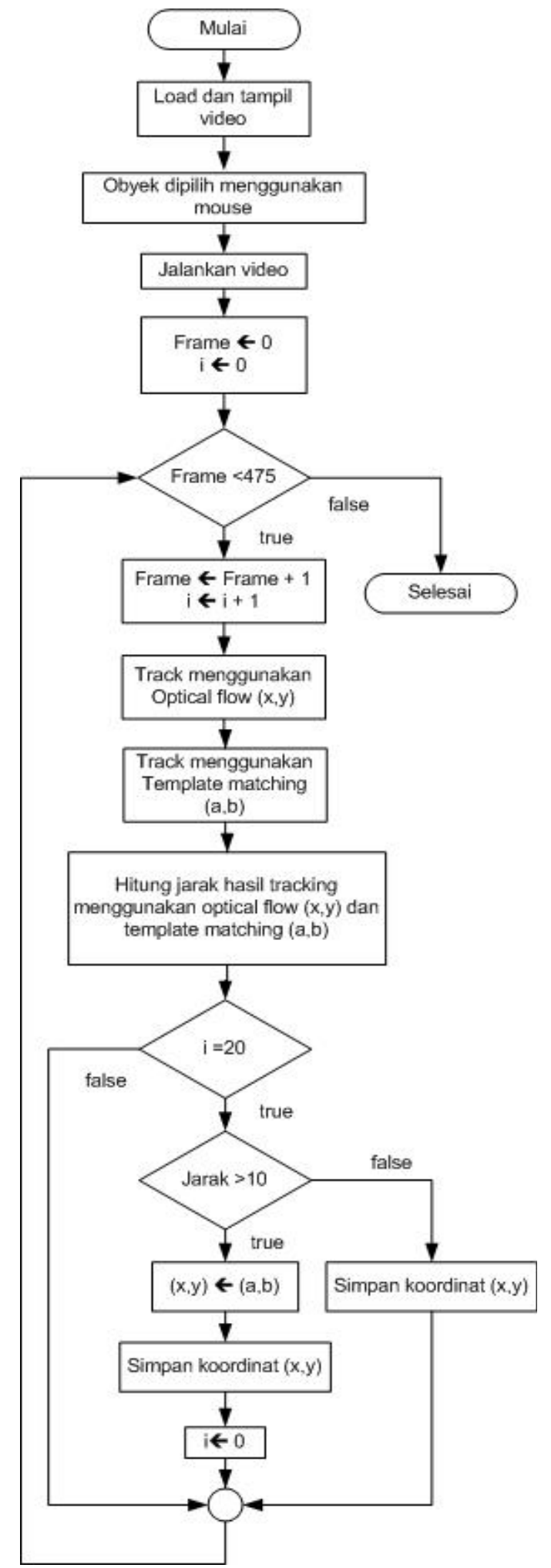

Gambar 2. Diagram alir program

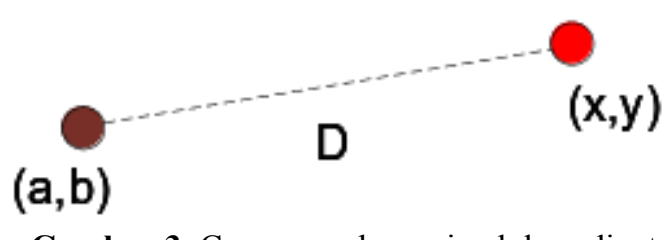

Gambar 3. Cara pengukuran jarak koordinat 


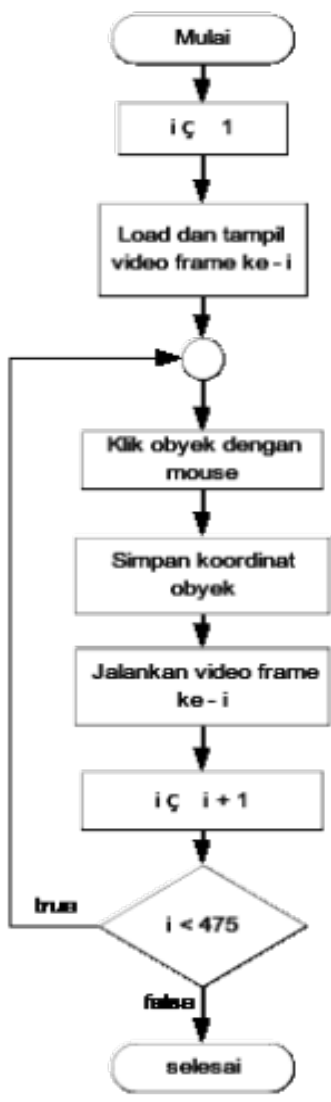

Gambar 4. Diagram alir pengambilan koordinat sebenarnya

Koordinat objek yang sebenarnya diambil dengan cara seperti yang ditunjukkan dalam diagram alir di Gambar 4. Pengambilan koordinat dimulai dengan menampilkan video frame pertama, objek terpilih dan koordinat objek langsung tersimpan. Video kembali dijalankan pada frame ke-2, objek dipilih koordinat langsung tersimpan, dan seterusnya sampai pada frame ke 474. Jadi, pengambilan koordinat objek dilakukan secara manual tiap frame.

Pengujian dilakukan dengan mengunggah video sepak bola. Pengguna memilih bola menggunakan mouse komputer. Gambar video pengujian ditunjukkan dalam Gambar 5, seperti yang digunakan dalam [4]. Bola dilacak dengan menerapkan algoritma gabungan dari optical flow dan template matching. Proses pengolahan sistem dilakukan menggunakan komputer dengan spesifikasi prosesor Intel core i3-2310m @ $2.1 \mathrm{GHz}$. Video yang diolah berukuran 630 x 360 piksel.

\section{Hasil dan Pembahasan}

Pada penelitian sebelumnya, dihasilkan galat jarak menggunakan optical flow dan template matching secara terpisah berturut-turut ditunjukkan dalam Gambar 7 dan Gambar 8 [4]. Hasil tersebut menunjukkan bahwa dengan menggunakan optical flow jika objek terhalang sesaat atau objek bergerak terlalu cepat, maka sistem tidak akan dapat mendeteksi objek lagi. Hal ini ditunjukkan nilai galat yang tidak dapat

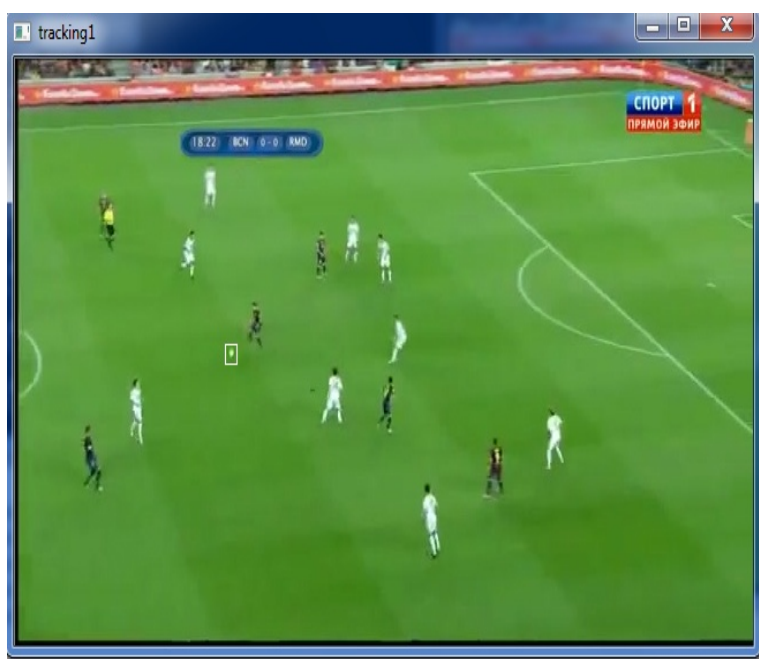

Gambar 5. Gambar video pengujian

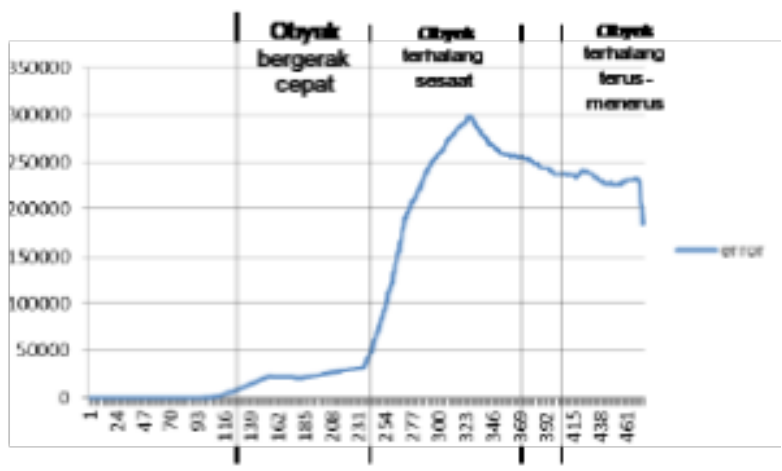

Gambar 6. Hasil galat jarak menggunakan algoritma optical flow [4]

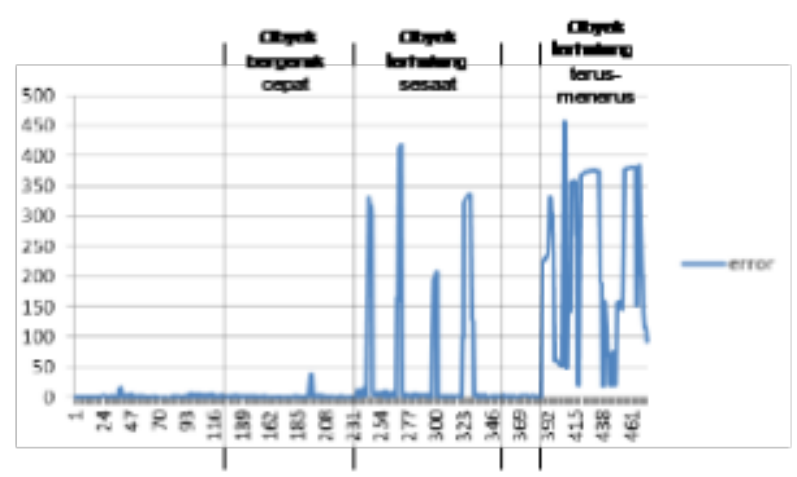

Gambar 7. Hasil error jarak menggunakan algoritma template matching [4]

mendekati nol [4]. Namun, untuk hasil menggunakan algoritma template macthing, ketika objek terhalang sesaat atau bergerak terlalu cepat, sistem masih bisa kembali mendeteksi objek. Hal ini ditunjukkan dengan perubahan nilai galat yang cukup besar. Nilai galat dihitung dengan menggunakan Persamaan 1.

Penelitian ini melakukan penggabungan algoritma optical flow dan template matching, yang disebut dengan algoritma hibrida, menggunakan diagram alir program seperti yang ditunjukkan dalam Gambar 2 . Nilai galat jarak dengan menggunakan algoritma hibrida tersebut ditunjukkan dalam Gambar 8. Nilai galat 


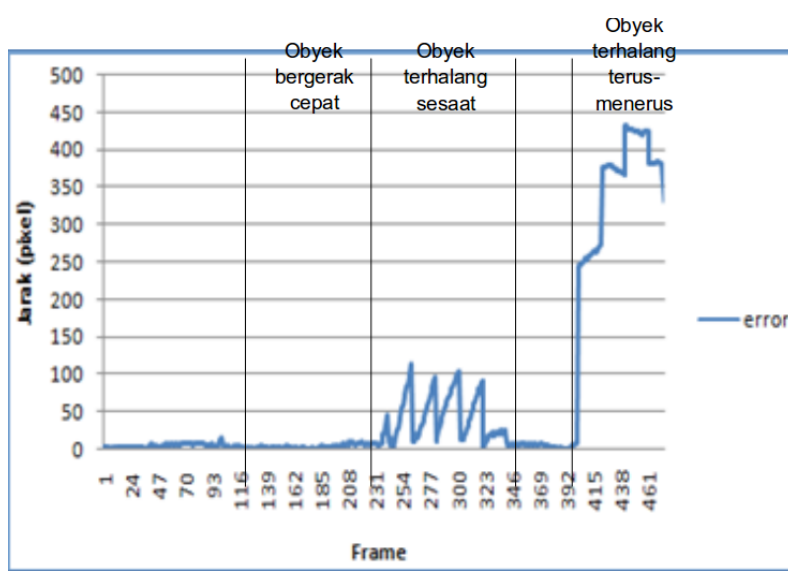

Gambar 8. Galat jarak koordinat hasil menggunakan algoritma hibrida

Tabel 1. Hasil perbandingan algoritma berdasarkan galat maksimum

\begin{tabular}{lcccc}
\hline No. & Kondisi & \multicolumn{3}{c}{ Galat Maksimum } \\
\cline { 3 - 5 } & & $\begin{array}{c}\text { Optical } \\
\text { flow } \\
\text { (piksel) }\end{array}$ & $\begin{array}{c}\text { Template } \\
\text { matching } \\
\text { (piksel) }\end{array}$ & $\begin{array}{c}\text { Hibrida } \\
\text { (piksel) }\end{array}$ \\
\hline 1. & Objek bergerak & 5000 & 40 & 12 \\
cepat & 300000 & 425 & 110 \\
2. & $\begin{array}{c}\text { Objek terhalang } \\
\text { sesaat }\end{array}$ & 360 & 430 \\
3. & $\begin{array}{c}\text { Objek terhalang } \\
\text { terus-menerus }\end{array}$ & 240000 & 460 & \\
\hline
\end{tabular}

tersebut menunjukkan bahwa bola sempat terhalang sesaat oleh pemain sehingga terjadi galat cukup besar antara frame ke-239 sampai 341, tetapi sistem masih dapat mendeteksi posisi bola kembali ditandai dengan mengecilnya nilai galat. Namun, galat meningkat mulai pada frame 409. Hal ini terjadi karena kondisi bola tidak terlihat jelas tertutup oleh pemain sehingga sistem mendeteksi objek yang berbentuk mirip bola dan terjadi nilai galat yang cukup besar. Algoritma kombinasi optical flow dan template matching yang diterapkan dalam sistem ini membutuhkan waktu komputasi selama 0.15 detik, sehingga terdapat 5 frame untuk setiap detiknya.

Hasil perbandingan ketiga algoritma berdasarkan nilai galat maksimum ditunjukkan dalam Tabel 1 . Dilihat dari nilai galat maksimalnya, dapat dinyatakan bahwa algoritma hibrida yaitu gabungan kombinasi algoritma optical flow dan template matching terbukti paling baik dibandingkan dengan algoritma optical flow dan template matching terpisah seperti yang dilakukan pada penelitian [4]. Demikian pula dalam hal kestabilan, algoritma ini lebih stabil dibandingkan menggunakan algortima optical flow dan template matching.

Hasil penelitian [5]-[10] menjelaskan keandalan sistem pelacakan yang dibangun, dimana sistem dapat melakukan deteksi dan pelacakan objek yang bergerak cepat dan terhalang sesaat. Namun, penelitian-penelitian tersebut tidak menjelaskan tentang kecepatan komputasi dan besar nilai galat jarak koordinat yang dihasilkan.
Nilai galat ini dapat digunakan sebagai referensi dalam keberhasilan pelacakan objek.

\section{KESIMPULAN}

Berdasarkan hasil pengujian, sistem pelacakan yang dibangun dengan menggabungkan algoritma optical flow dan template matching ini dapat bekerja dengan baik. Sistem dapat melakukan pelacakan meskipun objek terhalang sesaat, memperkecil nilai galat maksimum serta lebih stabil. Namun, diperlukan adanya penelitian lebih lanjut untuk memperkuat pelacakannya sehingga dapat lebih memperkecil nilai galatnya lagi.

\section{UCAPAN TERIMA KASIH}

Penelitian ini dibiayai dalam Program Penelitian bagi Dosen Pemula P3M Politeknik Negeri Jember. Ucapan terima kasih juga disampaikan kepada Jurusan Teknik yang telah memberikan fasilitas alat dan laboratorium dalam pelaksaanaan penelitian ini.

\section{Daftar Pustaka}

[1] S. Shirgeri, P. U. Naik, G. R. Udupi, and G. A. Bidkar, "Design and Development of Optical Flow Based Moving Object Detection and Tracking (OMODT) System," International Journal of Computational Engineering Research, vol. 03, no. 4, pp. 65-72, 2013.

[2] M. Sahasri, C. Gireesh, "Object Motion Detection and Tracking for Video Surveilance," International Journal of Engineering Trends and Technology (IJETT)., Special Issue, pp. 161-164, April 2017.

[3] A. Salhi, and A. Y. Jammoussi, "Object Tracking System using Camshift, Meanshift and Kalman Filter," International Journal Of Electronics And Communication Engineering, vol. 6, no.4, pp. 421-426, 2012.

[4] A. Fahriannur, R. Mardiyanto, and D. Purwanto, "Sistem Tracking Obyek Menggunakan Kamera untuk Aplikasi Target Locking," in Proceeding the 14th Seminar on Intelligent technology And Its Applications, 24 September 2013, Surabaya, 2013.

[5] L. Dan, J. Dai-Hong, B. Rong, Z. Wen-Jing, Z. Wen-Jing, and W. Chao, "Moving Object Tracking Method Based on Improved LucasKanade Sparse Optical Flow Algorithm," in 2017 International Smart Cities Conference (ISC2), 1417 September 2017, Wuxi, China, 2017.

[6] C. Xiu, and X. Pan, "Tracking Algorithm Based On The Improved Template matching," in 2017 Chinese Control and Decision Conference (CCDC), 28-30 Mei 2017, Chongqing, China, 2017.

[7] S. Battiato, G. M. Farinella, A. Furnari, G. Puglisi, A. Snijders, and J. Spiekstra. "Vehicle Tracking Based on Customized Template Matching," in 2014 International Conference on Computer 
Vision Theory and Applications (VISAPP), 5-8 Januari 2014, Lisbon, Portugal, 2014.

[8] M. Lalonde, S. Foucher, L. Gagnon, E. Pronovost, M. Derenne, and A. Janelle, "A System to Automatically Track Humans and Vehicles with a PTZ Camera," in SPIE Defense \& security : Visual information Processing XVI, 10 April 2007, Orlando, Florida, USA, 2007.

[9] N. Prabhakar, V. Vaithiyanathan, A. P. Sharma, and A. Singh, "Object Tracking using Frame Difference and Template Matching," Research Journal of Applied Sciences, Engineering and Technology, vol. 4, no. 24, pp. 5497-5501, 2012.

[10] E. Parrila, D. Ginestar, J. L. Hueso, J. Riera, and J. R. Torregrosa, "Handling Occlusion in Optical Flow Algorithm for Object Tracking," Computers \& Mathematics with Application, vol. 56, no. 3, pp. 733-742, 2008.

[11] N. Nidhi, "Image Processing and Object Detection," International Journal of Applied Research, vol. 1, no. 9, pp. 396-399, 2015.
[12] M. S. Kalas, "Real Time Face Detection and Tracking Using OpenCV," International Journal of Soft Computing and Artificial Intelligence, vol. 2, no.1, pp. 41-44, 2014.

[13] B. Tharanidevi, R. Vadivu, and K. B. Sethupathy, "Moving Object Tracking Distance and Velocity Determination Based on Background Subtraction Algorithm," IOSR Journal of Electronics and Communication Engineering, vol. 8, no. 1, pp. 6166, 2013.

[14] M. Sharma, and A. Batra, "Analysis of Distance Measures in Content Based Image Retrieval," Global Journal of Computer Science and Technology, vol. 14, no. 2, pp. 11-16, 2014.

[15] J. C. Elizondo-Leal, E. F. Parra-González, and J. G. Ramírez-Torres, "The Exact Euclidean Distance Transform: A New Algorithm for Universal Path Planning," International Journal of Advanced Robotic System, vol. 10, no. 6, pp. 1$10,2013$. 